\title{
ANALISIS FAKTOR-FAKTOR YANG MEMPENGARUHI KEPUTUSAN MAHASISWA DALAM MEMILIH PROGRAM STUDI DI FAKULTAS ILMU KESEHATAN UNIVERSITAS MUHAMMADIYAH TANGERANG
}

\author{
Eneng Wiliana \\ Universitas Muhammadiyah Tangerang \\ Email :nengwili.umt@gmail.com
}

\begin{abstract}
ABSTRAK
Penelitian ini bertujuan untuk mengetahui faktor-faktor yang mempengaruhi keputusan mahasiswa dalam memilih program studi di Fakultas Ilmu Kesehatan Universitas Muhammadiyah Tangerang sebagai tempat kuliah. Penelitian ini dilaksanakan di Fakultas Ilmu Kesehatan UMT dengan jumlah responden sebanyak 147 orang. Penelitian ini merupakan penelitian kuantitatif, yang bersifat eksploratif. Jenis data yang digunakan dalam penelitian ini adalah data primer. Data yang diperoleh diuji dengan menggunakan analisi faktor. Hasil penelitian menunjukan bahwa terdapat dua faktor yang mempengaruhi keputusan mahasiswa dalam memilih program studi di Fakultas Ilmu Kesehatan UMT sebagai tempat kuliah yaitu faktor internal yang mencakup tempat, harga, produk, fisik dan promosi. Faktor eksternal yaitu keluarga, pendapatan keluarga dan kemauan sendiri.
\end{abstract}

Kata Kunci : Faktor analisis, keputusan mahasiswa

\section{ABSTRACT}

This study aims to determine the factors that influence student decisions in choosing a study program at the Faculty of Health Sciences Muhammadiyah University of Tangerang as a place of college. This research was conducted at the Faculty of Health Sciences UMT with the number of respondents as many as 147 people. This research is a quantitative research, which is explorative. The type of data used in this study is the primary data. The data obtained were tested using factor analysis. The results showed that there are two factors that influence the decision of the students in choosing the study program in the Faculty of Health Sciences UMT as a place of lectures are internal factors that include place, price, product, physical and promotion. External factors are family, family income and self-will.

Keywords: Factors analysis, student decisions

\section{LATAR BELAKANG}

Pendidikan menjadi hal yang utama bagi setiap insan, terutama untuk menambah wawasan. Pendidikan sendiri memiliki jenjang atau tingkatan tertentu bagi mereka yang ingin menempuhnya. Pendidikan juga menyediakan jurusanjurusan ilmu yang disesuaikan dengan minat para peserta didik. Melalui pendidikan, wawasan seseorang akan semakin maju. Hal ini tentu memberi begitu banyak manfaat bukan hanya secara individu, melainkan juga bagi negara pada umumnya. Pendidikan menjadi hal penting yang tidak boleh ditinggalkan. Sebab dengan adanya pendidikan banyak hal yang bisa dilakukan.

Pendidikan adalah wadah untuk membangun masa depan yang cerah dengan pondasi yang kuat. Pendidikan adalah ujung tombak kemajuan suatu bangsa, semakin tinggi tingkat pendidikan masyarakat suatu bangsa, semakin disegani 
dan dihargai bangsa itu. Manusia yang berpendidikan akan membawa perubahan yang signifikan dalam berbagai bidang demi kesejahteraan manusia lainnya dan akan menularkan ilmunya kepada generasi penerusnya.

Saat ini berbagai program pendidikan yang menarik telah banyak ditawarkan oleh banyak perguruan tinggi, namun demikian memilih perguruan tinggi menjadi kesulitan dan keunikan tersendiri mengingat banyak sekali perguruan tinggi yang menawarkan dan mempromosikan berbagai program yang ada di perguruan tinggi sehingga calon mahasiswa dihadapkan pada situasi untuk memilih program-program tersebut.

Banyak faktor yang harus dipertimbangkan sebelum seorang calon mahasiswa menjatuhkan pilihan kepada salah satu perguruan tinggi yang diminati. Proses pengambilan keputusan mungkin akan dimulai dengan penetapan tujuan lalu mengembangkan alternatif dan akhirnya menentukan pilihan yang terbaik. Sebagian orang mungkin akan melakukan pilihan secara spontan tanpa perencanaan karena tergiur oleh promosi, pelayanan, fasilitas gedung dan lain-lain. Tentu dalam menentukan pilihan kuliah memerlukan proses rasional karena akan berakibat jangka panjang dan terkait dengan pengorbanan yang besar, mulai dari waktu, persiapan, dana, dan sikap mental dari mahasiswa tersebut.

Universitas Muhammadiyah Tangerang berusaha untuk selalu mendapat tempat di masyarakat sebagai perguruan tinggi yang dipercaya dan berkualitas. UMT yang berdiri pada tahun 2009 berhasil menjaring mahasiswa yang cukup luar biasa, bahkan bisa menyaingi perguruan tinggi yang ada sebelumnya. Universitas Muhammadiyah Tangerang mempunyai tujuh fakultas diantaranya adalah Fakultas Ilmu Kesehatan yang cukup diminati oleh masyarakat karena banyak masyarakat yang berasumsi bahwa lulusan kesehatan akan mudah mendapatkan pekerjaan. akan tetapi penerimaan mahasiswa di Fakultas Ilmu Kesehatan selalu dibatasi mengingat lahan prakteknya sangat terbatas. Fakultas Ilmu Kesehatan terdiri dari dua prodi yaitu prodi Sarjana Keperawatan dan prodi D-III Kebidanan. Dari kedua prodi tersebut mahasiaswa prodi sarjana keperawatan saat ini lebih banyak diminati seperti yang terlihat pada tabel dibawah ini :

Tabel 1

Jumlah Mahasiswa Fakultas Ilmu Kesehatan UMT

\begin{tabular}{rlccccc}
\hline \multirow{2}{*}{ No } & Prodi & $\begin{array}{c}\text { Tahun Akademik } \\
\text { (Smt II ) }\end{array}$ & $\begin{array}{c}\mathbf{2 0 1 6 / 2 0 1 7} \\
\text { ( Smt IV ) }\end{array}$ & $\begin{array}{c}\mathbf{2 0 1 5 / 2 0 1 6} \\
\text { ( Smt VI ) }\end{array}$ & $\begin{array}{c}\text { 2014/2015 } \\
\text { ( Smt VIII ) }\end{array}$ & Jumlah \\
\hline 1 & $\begin{array}{l}\text { S-1 } \\
\text { Keperawatan } \\
\text { Ners } \\
\text { (Profesi) }\end{array}$ & 78 & 69 & 72 & 76 & 295 \\
2 & $\begin{array}{l}\text { Keperawatan } \\
\text { D-III } \\
\text { Kebidanan }\end{array}$ & 51 & 38 & 50 & 53 \\
\hline
\end{tabular}

Sumber : Bagian Akademik dan Kemahasiswaan Fikes Tahun 2018

Jika dilihat dari sisi kuantitas, jumlah mahasiswa perawat lebih banyak dibanding dengan mahasiswa kebidanan, namun apakah peningkatan jumlah mahasiswa ini semata-mata karena program studi keperawatan memiliki daya tarik tersendiri di mata mahasiswa, untuk itu penelitian ini bertujuan untuk mengetahui faktor-faktor 
apa saja yang mempengaruhi keputusan mahasiswa dalam memilih program studi sarjana keperawatan.

\section{KAJIAN PUSTAKA}

\section{Jasa Layanan Pendidikan}

Dalam mengembangkan dan meningkatkan kualitas sumber daya manusia jasa pendidikan memegang peranan penting. Akan tetapi, minat dan perhatian pada aspek kualitas jasa pendidikan bisa dikatakan baru berkembang dalam satu dekade terakhir. Keberhasilan jasa pendidikan ditentukan dalam memberikan pelayanan yang berkualitas kepada para pengguna jasa pendidikan tersebut (siswa, stakeholder, masyarakat)

Lupiyadi Rambat ( 2006:6) menyebutkan, "Secara sederhana layanan pendidikan bisa diartikan dengan jasa pendidikan. Kata jasa ( service) itu sendiri memiliki beberapa arti, mulai dari pelayanan pribadi ( personal service) sampai pada jasa sebagai suatu produk". Pendidikan sebagai produk jasa merupakan sesuatu yang tidak berwujud akan tetapi dapat memenuhi kebutuhan konsumen yang diproses dengan menggunakan atau tidak menggunakan bantuan produk fisik dimana proses yang terjadi merupakan interaksi antara penyedia jasa dengan pengguna jasa yang mempunyai sifat yang tidak mengakibatkan peralihan hak atau kepemilikan. Jasa bukan barang melainkan suatu proses atau aktivitas yang tidak berwujud.

Pemasaran jasa pendidikan menurut Kotler dan Fox dalam ( Lupiyoadi ; 2009 ) menawarkan jasa dengan bauran pemasaran 7P : Program , Harga ( Price), Tempat ( Place ), Promosi (Promotion), Proses (Process), Fasilitas Fisik ( Physical fasilities), orang ( People).

\section{Pengambilan Keputusan}

Menurut Swastha dan Handoko (2011) berpendapat bahwa lima peran individu dalam sebuah keputusan membeli, yaitu:
Pengambilan inisiatif (initiator): individu yang mempunyai inisiatif pembelian barang tertentu atau yang mempunyai kebutuhan atau keinginan tetapi tidak mempunyai wewenang untuk melakukan sendiri. Orang yang mempengaruhi (influencer): individu yang mempengaruhi keputusan untuk membeli baik secara sengaja maupun tidak sengaja.

Pengambilan keputusan menurut Baron \& Bayne (2008) adalah suatu proses melalui kombinasi individu atau kelompok dan mengintegrasikan informasi yang ada dengan tujuan memilih satu dari berbagai kemungkinan tindakan. Sedangkan pengambilan keputusan juga didefinisikan oleh Sweeney dan Mc Farlin ( dalam Sarwono \& Meinarno, 2009 ) sebagai suatu proses mengevaluasi pilihan-pilihan yang ada untuk mendapatkan hasil yang diharapkan.

\section{Model-model Pengambilan Keputusan}

Schiffman-Kanuk menerangkan tentang definisi perilaku konsumen sebagai perilaku yang ditunjukan oleh konsumen dalam pencariannya untuk membeli, menggunakan, mengevaluasi, membuang produk, jasa dan ide yang mungkin dapat memenuhi kebutuhan mereka.

Model lima tahap proses keputusan pembelian atau model tingkat konsumen menurut kotler ( 2008:184) yaitu pengenalan masalah, pencarian informasi, evaluasi alternatif, keputusan pembelian, dan perilaku pasca pembelian. Proses pembelian dimulai jauh sebelum pembelian aktual dan mempunyai konsekuensi dalam waktu lama setelahnya. Model dari Schiffman-Kanuk merefleksikan adanya proses kognitif atas pemecahan masalah yang dialami oleh konsumen dan terdiri tiga komponen utama yaitu input, proses dan output. Motivasi menurut SchiffmanKanuk (2007:72) dapat digambarkan sebagai tenaga pendorong dalam setiap individu yang membuat mereka untuk bertindak atau melakukan reaksi yang muncul untuk memenuhi kebutuhannya. 
Para individu secara sadar maupun tidak sadar berusaha untuk mengurangi ketegangannya dengan cara memenuhi kebutuhan mereka yang belum terpenuhi.

Hal tersebut juga dialami oleh mahasiswa FIKes UMT yang telah menjatuhkan pilihannya pada program studi sarjana keperawatan. Alasan-alasan atau faktor-faktor pertimbangan yang mereka lalui pada dasarnya berbeda-beda satu sama lain juga memiliki perilaku yang berbeda setelah keputusan tersebut diambil.

\section{Faktor-faktor yang Mempengaruhi Keputusan Mahasiswa}

Mahasiswa dalam memilih jurusan atau program studi yang akan mereka tempuh pada perguruan tinggi merupakan sebuah cara dalam perencanaan karirnya. Dalam proses memilih atau memutuskan seringkali seseorang dihadapkan pada kebingungan, hal ini tidak bisa dipungkiri karena jurusan yang dipilih akan menjadi gerbang pertama dalam memilih karir dimasa depan. Banyak faktor yang harus diperhitungkan dan dipikir masak-masak. Dari berbagai penelusuran literatur, diketahui bahwa banyak faktor yang paling banyak menentukan dalam memilih perguruan tinggi adalah ketertarikan atau daya tarik. Disamping itu keputusan seseorang untuk menentukan pilihan dipengaruhi oleh faktor lingkungan internal dan faktor lingkungan eksternal.

Terdapat dua faktor yang mempengaruhi pemasaran secara keseluruhan yaitu faktor lingkungan internal dan lingkungan eksternal ( Angiopora, 2002:50) :

1. Lingkungan Internal adalah pengaruh yang bersumber dari dalam perusahaan, yang secara langsung akan berpengaruh kepada kinerja perusahaan secara keseluruhan salah satu faktor yang harus dianalisis dalam lingkungan internal adalah marketing mix pada jasa pendidikan yaitu, product, price, place, promotion, people, physical evidence dan process.
2. Lingkungan eksternal adalah suatu pengaruh lingkungan yang berasal dari luar perusahaan baik yang sangat dekat dengan perusahaan maupun agak jauh, dan secara langsung atau tidak langsung mempengaruhi kegiatan perusahaan keseluruhan. Lingkungan eksternal yang harus diperhatikan adalah keluarga, pendapatan keluarga, kemauan sendiri, dan kelompok acuan.

\section{METODOLOGI PENELITIAN}

Penelitian ini merupakan penelitian kuantitatif, yang bersifat eksploratif, yaitu suatu penelitian yang bermaksud mengeksplorasi variabel-variabel atau indikator-indikator dominan yang membentuk faktor-faktor. Populasi dalam penelitian ini adalah Mahasiswa Prodi Keperawatan Fakultas Ilmu Kesehatan Universitas Muhammadiyah Tangerang angkatan tahun akademik 2016/2017 dan tahun akademik 2017/2018 dengan total 147 mahasiswa. Dari populasi 147 mahasiswa, akan diambil sampel sebanyak 107 mahasiswa. Pengambilan sampel dengan menggunakan rumus Slovin. Penelitian ini menggunakan teknik pengumpulan data berupa kuesioner/angket.

Subyek penelitian adalah mahasiswa FIKes Prodi S-1 Keperawatan, sedangkan objeknya adalah Faktor Produk, harga, promosi, orang, tempat, proses, bukti fisik, pendapatan keluarga, kelompok acuan, kemauan sendiri dan keluarga. Jenis data yang digunakan dalam penelitian ini adalah data primer yang dikumpulkan dengan teknik kuesioner, kemudian dianalisis dengan menggunakan analisis faktor.

\section{HASIL DAN PEMBAHASAN}

\section{Hasil}

Berdasarkan hasil analisis faktor dengan menggunakan program SPSS maka diperoleh hasil perhitungan SPSS 
Deskripsi Data

Tabel 2. Hasil Pengumpulan Data

\begin{tabular}{lcc}
\hline \multicolumn{1}{c}{ Keterangan } & Jumlah & \% \\
\hline $\begin{array}{l}\text { Kuesioner yang } \\
\text { terkumpul }\end{array}$ & 147 & 100 \\
$\begin{array}{l}\text { Kuesioner yang } \\
\text { memenuhi syarat }\end{array}$ & 147 & 100 \\
\hline
\end{tabular}

Bedasarkan data disamping ditunjukan bahwa jumlah kuesioner yang terkumpul sebanyak $100 \%$ dan kuesioner yang memenuhi syarat untuk penelitian $100 \%$

\section{Tabel 3}

$\mathrm{KMO}$ and Bartlett's Test

\begin{tabular}{llr}
\hline Kaiser-Meyer-Olkin Measure of &, 784 \\
Sampling Adequacy. & Approx. Chi- & \\
Bartlett's Test of & Square & 229,511 \\
Sphericity & df & 28 \\
& Sig. &, 000
\end{tabular}

Berdasarkan tabel diatas dapat dijelaskan bahwa Uji Barlett's Tes of Sphericity ( BTO ) besar dan signifikan, dengan hasil Approx Chi Square sebesar 229.511 dan Significance-nya sebesar 0,000. Sedangkan dilihat dari hasil uji Kaisar-Meyer olkin ( KMO ) Of Sampling Adequacy yaitu sebesar 0.784 yang berarti ketepatan penggunaan analisis faktor yang dapat dipertanggung jawabkan. Karena nilai Kaisar-Meyer olkin ( KMO ) nya sudah diatas 0.5 dan signifikansi jauh dibawah 0,05 $(0,000<0,05)$ menunjukan bahwa analisis tersebut tepat.untuk nilai KMO dan Barlett's Tes pada nilai Chi Square sebesar 229,511 dengan nilai sig 0,000 hal ini menunjukan bahwa adanya korelasi antar variabel dan layak untuk proses lebih lanjut.

Tabel 4

Total Variance Explained

Total Variance Explained

\begin{tabular}{|c|c|c|c|c|c|c|}
\hline \multirow[b]{2}{*}{ Component } & \multicolumn{3}{|c|}{ Initial Eigenvalues } & \multicolumn{3}{|c|}{ Extraction Sums of Squared Loadings } \\
\hline & Total & $\%$ of Variance & Cumulative \% & Total & $\%$ of Variance & Cumulative \% \\
\hline 1 & 3,255 & 40,688 & 40,688 & 3,255 & 40,688 & 40,688 \\
\hline 2 & 1,349 & 16,859 & 57,547 & 1,349 & 16,859 & 57,547 \\
\hline 3 & ,838 & 10,471 & 68,018 & & & \\
\hline 4 & ,694 & 8,681 & 76,698 & & & \\
\hline 5 & ,650 & 8,130 & 84,828 & & & \\
\hline 6 & ,472 & 5,900 & 90,728 & & & \\
\hline 7 & ,411 & 5,142 & 95,870 & & & \\
\hline 8 & ,330 & 4,130 & 100,000 & & & \\
\hline
\end{tabular}

Extraction Method: Principal Component Analysis.

Tabel 5

Faktor-Faktor yang mempengaruhi keputusan mahasiswa dalam memilih jurusan di FIKes UMT

\begin{tabular}{cccc}
\hline Faktor & Eigenvalue & Variabel & Factor Loading \\
\hline Faktor 1 & 3.255 & Tempat & 0.735 \\
Faktor Lingkungan & & Harga & 0.631 \\
Internal & & Produk & 0.494 \\
& & Fisik & 0.517 \\
& & Promosi & 0.315 \\
\hline Faktor 2 & \multirow{2}{*}{1.349} & Keluarga & 0.635 \\
Faktor Lingkungan & & Pendapatan keluarga & 0.711 \\
Eksternal & & Kemauan sendiri & 0.566 \\
\hline
\end{tabular}


Berdasarkan tabel 5, terdapat dua faktor yang mempengaruhi mahasiswa dalam memilih jurusan di FIKes UMT sebagai tempat kuliah yaitu (1) faktor lingkungan internal yang meliputi tempat, harga, fisik, produk, dan promosi. (2) faktor lingkungan eksternal yang meliputi keluarga, pendapatan keluarga, dan kemauan sendiri. Faktor 1 memiliki total eigenvalue sebesar 3,255 dengan nilai varian sebesar $40,688 \%$, dan faktor 2 memiliki total eigenvalue sebesar 1,349 dengan nilai varian sebesar $16,859 \%$. Kedua faktor tersebut mempunyai total percentage of variance sebesar $57,547 \%$ terhadap keputusan mahasiswa dalam memilih jurusan di FIKes UMT sebagai tempat kuliah dan sisanya sebesar $42,46 \%$ dipengaruhi oleh faktor lain diluar model seperti situasi, kondisi dan informasi serta kelompok acuan.

Berdasarkan pengujian hipotesis konseptual, untuk menentukan dimensi atau faktor yang paling dominan mempengaruhi mahasiswa dalam memutuskan mmilih Prodi digunakan parameter koefisien varimax rotation. Diambil dari dimensi atau faktor keputusan mahasiswa yang paling mendekati +1 atau mendekati -1 . Nilai yang mendekati 1 diawali oleh nilai 0,5 sedangkan nilai yang mendekati -1 diawali oleh -0,5.

Berdasarkan Tabel 5 maka faktor yang paling dominan mempengaruhi keputusan mahasiswa dalam memilih program studi di FIKes UMT adalah faktor internal yang memiliki total nilai eigenvalue sebesar 3,255 dengan nilai varian sebesar 40,688\%, faktor internal yang mempengaruhi adalah faktor tempat, harga,fisik, produk dan promosi.

\section{PEMBAHASAN}

Hasil penelitian ini sesuai dengan teori yang dinyatakan oleh Angipora (2014) yaitu terdapat dua faktor yang mempengaruhi pemasaran secara keseluruhan yaitu faktor lingkungan internal dan lingkungan eksternal.
Berdasarkan analisis yang telah dilakukan, mahasiswa dalam memilih program studi di FIKes UMT sebagai tempat kuliah adalah faktor internal yang meliputi tempat, harga, fisik/fasilitas, produk dan promosi. Faktor lingkungan eksternal yang mempengaruhi mahasiswa dalam memilih program studi di FIKes UMT adalah keluarga, pendapatan keluarga dan kemauan sendiri. Dari kedua faktor tersebut faktor yang paling dominan mempengaruhi mahasiswa dalam memilih program studi di FIKes UMT untuk faktor lingkungan internal adalah tempat dengan factor loading sebesar 0.735 angka tersebut menjelaskan bahwa faktor lokasi mempengaruhi keputusan mahasiswa dalam memilih program studi di FIKes UMT dikarenakan lokasi sekolah sangat strategis, kemudian faktor harga dengan factor loading 0.631 angka tersebut menjelaskan bahwa harga juga mempengaruhi keputusan mahasiwa dalam memilih program studi di FIKes UMT. Faktor fisik dengan factor loading sebesar 0.517 , faktor produk dan faktor promosi mempunyai factor loading yang rendah yaitu sebesar 0.494 dan 0.315 , artinya faktor fisik / fasilitas FIKes UMT masih sangat kurang dan begitu juga promosi yang dilakukan FIKes UMT masih belum menyebar ke daerah-daerah terutama kabupaten Tangerang.

Sedangkan dilihat dari faktor lingkungan eksternal adalah pendapatan keluarga dengan factor loading 0.711 angka tersebut menjelaskan bahwa pendapatan keluarga sebagai salah satu faktor yang mempengaruhi keputusan mahasiswa karena status ekonomi orang tua akan berpengaruh dalam hal kemampuan untuk memenuhi biaya pendidikan. Faktor keluarga dengan factor loading sebesar 0.635 artinya keinginan keluarga atau dukungan keluarga sangat mempengaruhi keputusan mahasiswa untuk memilih program studi. Faktor kemauan sendiri dengan factor loading sebesar 0.566 artinya kemauan yang ada pada mahasiswa itu sendiri dalam menentukan pilihannya 
sangat berpengaruh kepada penentuan keputusan untuk memilih jurusan / program studi.

\section{KESIMPULAN DAN SARAN}

Berdasarkan hasil pengujian statistik dan hipotesis serta pembahasan yang telah dilakukan, maka dapat ditarik kesimpulan bahwa faktor yang mempengaruhi keputusan mahasiswa dalam memilih program studi di Fakultas Ilmu Kesehatan UMT adalah faktor lingkungan internal yang meliputi tempat, harga, produk, fisik dan promosi dengan nilai eigenvalue sebesar 3.255 dengan loading factor yang paling dominan adalah variabel tempat sebesar 0.735. Untuk faktor lingkungan eksternal yaitu keluarga, pendapatan keluarga dan kemauan sendiri mempunyai nilai eigenvalue sebesar 1.349, dengan loading factor yang paling dominan adalah variabel pendapat keluarga. Faktor yang paling dominan mempengaruhi mahasiswa dalam memilih program studi di FIKes UMT adalah faktor lingkungan internal.

Berdasarkan hasil penelitian dan kesimpulan yang telah dipaparkan, maka saran yang dapat disampaikan oleh peneliti sebagai berikut : (1) melihat dari faktor lingkungan internal bahwa keputusan mahasiswa dalam memilih program studi cukup baik, maka pihak intstitusi yang berperan dalam meningkatkan mutu dan kompetensi yang ada harus lebih baik lagi.

(2) Faktor Fhysical Evidence atau struktur fisik dari sebuah institusi pendidikan yang merupakan komponen utama dalam membentuk kesan sebuah Institusi / perusahan. Physical evidence memiliki peranan penting untuk menarik minat konsumen agar datang ke suatu perusahaan dan melakukan pembelian. (3) Kegiatan Promosi juga perlu ditingkatkan kembali agar keberadaan FIKes UMT diketahui oleh masyarakat dan calon mahasiswa. FIKes UMT agar lebih kreatif lagi dalam melakukan sosialisasi tentang Fakultas Ilmu Kesehatan dengan dapat mendatangi sekolah-sekolah SMA/SMK guna memberikan arahan tentang jurusan / program studi yang ada di FIKes beserta keunggulannya. (4) FIKes UMT dan pemerintah diharapkan dapat mensosialisasikan jurusan/program studi yang ada didalamnya dan informasi lulusan yang dapat diserap oleh industri dengan baik, dapat berwirausaha mandiri, maupun melanjutkan studi ke jenjang yang lebih tinggi lagi sehingga orang tua dan mahasiswa mengetahui prospek lulusan.

\section{DAFTAR PUSTAKA}

Alma B dan Hurriyati R. 2008. Manajemen Corporate \& Strategi Pemasaran Jasa Pendidikan. Bandung: Alfabeta.

Alma B, 2009. Dasar-Dasar Bisnis dan Pemasaran. Bandung: Alfabeta.

Angipora, Marius P. 2014. Dasar-dasar Pemasaran. Jakarta: PT Raja Grafindo Persada.

Atmaja L. Setia, Ph.D. 2009. Statistika untuk bisnis dan ekonomi. Yogyakarta: Andi.

Bawantara, Agung. 2007. Lulus SMA Kuliha Dimana ?Panduan Memilih Program Studi. Jakarta : PT.Kawan Pustaka.

Ghozali,Imam. 2006. Aplikasi Analisis Multivariate Dengan Program SPSS. Semarang : Badan Penerbit Universitas Diponegoro.

Hurriyati R, 2008. Bauran Pemasaran dan Loyalitas Konsumen, Bandung: Alfabeta.

I Dewa Ayu Juli Artini, I Ketut Kirya, I Wayan Suwendra, 2014, Faktor-faktor yang Mempengaruhi Keputusan Mahasiswa Dalam Memilih Jurusan di Fakultas Ekonomi dan Bisnis ( FEB ) Universitas Pendidikan Ganesha ( UNDIKSHA) Sebagai Tempat Kuliah, e-Journal Bisma Universitas Pendidikan Ganesha Jurusan Manajemen ( Volume 2 Tahun 2014 ) 
Kotler, Philip, Keller, 2007. Manajemen Pemasaran. Edisi Keduabelas Jilid 2, Alih bahasa oleh Benyamin Molan. Jakarta : PT. Macanan Jaya Cemerlang

Lupiyoadi R, 2006. Manajemen Pemasaran Jasa ( Edisi II ), Jakarta: Salemba Empat.

Mc.Carthy, E-Jerome dan Wiliam D.Pereault Jr. 2004. Dasar-Dasar Pemasaran, Edisi Bahasa Indonesia. Alih Bahasa Agus Maulana. Jakarta : Penerbit Erlangga.

Muliadi, Erlan. 2011. Pemasaran Pendidikan. Tersedia pada http://erlanmuliadi.blogspot.com/2011 /06/pemasaran-pendidikan.html. (diakses tanggal 8 Januari 2018 )

Testian Yushli ,2015 Analisis FaktorFaktor yang Mempengaruhi Keputusan Mahasiswa Memilih Program Studi Pendidikan Ekonomi FKIP UNS ( Studi pada Angkatan 2014 dan 2015 ), Skripsi Program Studi Pendidikan Ekonomi FKIP, Universitas Sebelas Maret Surakarta.

Tjiptono F. 2008. Strategi Pemasaran, Edisi III. Yogyakarta: CV. Andi Offset Sugiyono. 2003. Metode Penelitian Administrasi. Bandung: Alfabeta. 2011. Metode Penelitian

Kuantitatif, Kualitatif dan $R \& D$, Bandung: Alfabeta.

Wahana Komputer, 2012. Shortcourse series SPSS 20, Yogyakarta: Andi 